\title{
Práticas culturais entre descendentes de italianos em Irati (PR): história do tempo presente, memória e nostalgia
}

Regiane Maneira*

\begin{abstract}
RESUMO
A cidade de Irati, localizada no centro-sul do Estado do Paraná, nas primeiras décadas do século $\mathrm{XX}$, recebeu um número significativo de descendentes de imigrantes italianos vindos de colônias próximas à Curitiba. Atraídos pela compra de terras na região para a prática da agricultura, esses grupos se instalaram em áreas rurais, nas quais muitas famílias permanecem até hoje. Atualmente, esses descendentes se organizaram e construíram, em 2016, um museu, "Casa dei Nonni", que possui um acervo de objetos e fotos doados pelos próprios moradores. Nosso intuito nesse artigo é discutir como nossa pesquisa, sobre os descendentes de italianos e o museu, pode dialogar e receber contribuições da História do Tempo Presente, campo historiográfico que surgiu na França no contexto pós-Segunda Guerra Mundial. Também buscamos refletir sobre os conceitos de memória e nostalgia.
\end{abstract}

Palavras-chave: Italianos. Tempo Presente. Memória. Nostalgia.

\section{Cultural practices between Italian descendants in Irati (Parana state): History of present time, memory and nostalgia}

\begin{abstract}
The city of Irati, located in the center-south of the State of Paraná, in the first decades of the twentieth century, received a significant number of descendants of Italian immigrants from colonies near Curitiba. Attracted by the purchase of land in the region for agriculture, these groups settled in rural areas, where many families remain today. Currently, these descendants organized themselves and built, in 2016, a museum, "Casa dei Nonni", which has a collection of objects and photos donated by the residents themselves. Our aim in this article is to discuss how our research on the descendants of Italians and the museum can dialogue and receive contributions from the History of Present Time, a historiographical field that emerged in France in the post-World War II context. We also seek to reflect on the concepts of memory and nostalgia.
\end{abstract}

Keywords: Italian. Present Time. Memory. Nostalgia.

Artigo recebido em 31 jan. 2019

Artigo aprovado em 24 abr. 2019

\footnotetext{
* Doutoranda em História pela Universidade do Estado de Santa Catarina - UDESC. Professora na Secretaria de Educação do Estado do Paraná. E-mail: maneiraregiane@yahoo.com.br.
} 
O desenvolvimento desta pesquisa está atrelado ao Programa de Pós-Graduação em História da Universidade do Estado de Santa Catarina, inserindo-se na área de concentração História do Tempo Presente. Esse campo de pesquisa possui como características centrais: o desenvolvimento de pesquisas nas quais as pessoas que vivenciaram determinados acontecimentos são capazes de dar seu testemunho e também a proximidade temporal entre o pesquisador e seu objeto. Ou seja, o historiador estuda um tempo do qual também faz parte. Em nosso artigo, temos como objetivo central compreender como os marcos conceituais desenvolvidos por alguns autores, sobre a História do Tempo Presente, permitem compreender o processo de construção e reafirmação da identidade italiana na região de Irati, estado do Paraná, a partir da construção do museu "Casa dei Nonni" ", inaugurado em 2016.

A História do Tempo Presente (HTP) teve seu início na França com a criação do Instituto de História do Tempo Presente (IHTP) em 1978. O primeiro diretor do instituto foi François Bédarida, que acreditava que o surgimento da HTP estava ligado ao "retorno vigoroso da história e da memória, uma busca ansiosa de identidade, a crise dos paradigmas das ciências sociais, enfim, um presente cheio de incertezas em relação a si mesmo e ao futuro num mundo que não sabia mais se iria desembocar em Prometeu ou Pandora (Bédarida, 1996, p. 219). A HTP nasceu em um contexto de incertezas não somente em relação ao presente e futuro da sociedade, mas também com seu próprio desenvolvimento enquanto área de conhecimento. As incertezas das quais fala Bédarida, diz respeito ao contexto histórico e social vivido na Europa na segunda metade do século XX, marcado pela crise ocasionada pela Segunda Guerra Mundial e a emergência da Guerra Fria. A história começa, então, a ser escrita a partir de novos anseios, pois surge um interesse em se pesquisar uma história da qual os próprios pesquisadores fizeram parte $e$ as pessoas que vivenciaram os fatos, como o holocausto, por exemplo, eram capazes de testemunhar. Em outras palavras, não era mais a história dos mortos, mas sim, dos vivos.

Eric Hobsbawm escreveu um artigo, na década de 1990, intitulado "O presente como história: escrever a história de seu próprio tempo" discorrendo entre outros assuntos, sobre os desafios que encontrou ao produzir o livro "A Era dos Extremos", no qual o autor teve que lidar com um recorte temporal do qual havia feito parte. Em outras de suas obras, Hobsbawm não havia passado pela experiência de escrever sobre um passado recente ou mesmo sobre acontecimentos que ainda estavam em percurso e que não se sabia sobre seus desfechos. Quando se escreve uma história do momento em que se está vivendo, não existe um distanciamento temporal entre historiador e objeto, o que faz com que o pesquisador "mergulhe" 
em uma sociedade e em um tempo dos quais também faz parte. Isso não significa dizer, que na HTP haverá a produção de uma única narrativa histórica, pois mesmo escrevendo sobre seu próprio tempo, "a vivência pessoal deste tempo molda inevitavelmente a forma como o vemos [...]" (Hobsbawn, 1995, p. 105).

A HTP era vista com desconfiança por parte dos historiadores, principalmente por trabalhar com acontecimentos que ainda não haviam sido tomados pela "poeira" dos arquivos, por "fazer uma história à quente" ou mesmo por não saber o desenrolar dos acontecimentos $e$ seus possiveis desdobramentos. Esses desafios tornam a HTP um campo historiográfico com características peculiares e que exigem, do historiador, um olhar atento sobre os fatos que estão sendo investigados.

Segundo François Dosse, a HTP tem “cartas" para serem jogadas (2012, p. 14). Essas "cartas" fazem da HTP um campo bastante frutífero para historiografia e com características particulares, trazendo à luz temas que, talvez, fossem negados por uma história de cunho tradicional. Uma das características da HTP que mais contribuem para nossa pesquisa é a presença de pessoas que vivenciaram, $e$ ainda vivenciam, determinados acontecimentos $e$ que são capazes de testemunhá-los.

Ao iniciar a pesquisa sobre os descendentes de italianos em Irati, percebemos que muitas fontes documentais, como fotos, cartas, livros e objetos, encontravam-se em arquivos particulares sob a guarda das próprias famílias. Por eu fazer parte desse grupo de descendentes, o acesso a tais documentos seria facilitado, porém, se restringia a um número pequeno de famílias, o que reduziria nosso campo de pesquisa. Além disso, essas fontes não contribuiriam significativamente para analisarmos sobre o processo de construção do museu "Casa dei Nonni", haja vista que é algo relativamente recente e as fontes escritas datam de períodos anteriores. Dessa forma, a utilização das fontes orais viria ao encontro dos nossos anseios na pesquisa, pois permitiriam a análise das narrativas daqueles que vivenciaram a construção do museu e que fazem parte do grupo dos descendentes de italianos ${ }^{2}$.

Salientamos que o uso da história oral, não é o que, exclusivamente, caracteriza a HTP. De acordo com Henry Rousso (2016, p. 259-260), o que caracteriza e ao mesmo tempo singulariza a HTP é a escrita de uma história na qual os atores, sejam ou não requisitados, estão presentes fisicamente, sendo que o historiador escreve sob a vigilância $e$ atenção destes. Em outras palavras, o desafio e a singularidade do historiador do tempo presente é escrever uma história na qual investigador e investigado fazem parte de um mesmo tempo.

Segundo Rousso (2016), a HTP é marcada muito mais pela presença dos atores de determinados acontecimentos, do que pelo seu testemunho. 
Definitivamente, a história do tempo presente se singulariza menos pela questão da testemunha do que pela própria presença dos atores, quer eles sejam ou não interrogados e requisitados. É a sua presença física, carnal, que obriga o historiador de um modo completamente diferente daqueles que trabalham com rastros. (Rousso, 2016, p. 259)

Isso implica em um cuidado redobrado por parte do historiador, haja vista que o que se escreve, pode ser refutado pelas pessoas que participaram dos acontecimentos, mesmo que suas narrativas não tenham sido utilizadas como fonte para a pesquisa. $\mathrm{O}$ uso do testemunho de pessoas que presenciaram ou presenciam determinados acontecimentos faz com que o historiador tenha uma preocupação em escrever uma história em que esses sujeitos se reconheçam na narrativa histórica, caso contrário, pode haver uma contestação por parte dessas pessoas. Em outras palavras, "pode-se com direito fazer o que quiser sobre os mortos [...] não se pode fazer isso com os vivos" (Rousso, 2016, p. 260).

Em nossa pesquisa essa preocupação é presente, pois a forma como interpretamos as práticas culturais dos descendentes de italianos, a partir de leituras de referenciais teóricos e da análise das fontes, podemos ter uma determinada interpretação e construir uma narrativa história que não esteja em consonância aos anseios dos descendentes de italianos que organizaram e frequentam espaços como o museu "Casa dei Nonni". Muitas pessoas podem criar expectativas, em relação a nossa pesquisa, que não condizem com nossa intenção, acreditando que nosso trabalho resgatará a tradição e reforçará a identidade étnica italiana, sendo que nosso intuito é compreender o processo histórico da construção identitária entre os descendentes de italianos.

Também temos que ter em mente outra questão cara à História e principalmente à HTP: a construção de "moradas provisórias", ou seja, a produção de narrativas inacabadas, pois a história ainda está em curso, uma vez que "a realidade continua a viver em seu presente" (Rousso, 2016, p. 262). Isso não significa que a HTP abandone o passado e lance sua atenção apenas ao presente, pelo contrário, o passado é entendido como algo não acabado e não encerrado (Rousso, 2016, p. 18). Entendemos que a construção do "ser italiano" em Irati pelos descendentes é algo que continua a ser elaborado cotidianamente através de práticas, narrativas, festas, religiosidade, etc., é uma história que está em curso e não sabemos quais serão seus desencadeamentos e reflexos.

Finalmente, temos um desafio que para mim tornar-se-á duplo: a distância com nosso objeto. Me refiro a um desafio duplo, porque, primeiramente, a HTP possui como uma de suas características a distância variável em relação ao objeto, pois a história ainda está em curso e, 
portanto, fazemos parte do mesmo presente que nosso objeto (Rousso, 2016, p.239-240). Minha distância em relação ao objeto é mais sensível ainda, não somente por fazer parte do mesmo presente, mas também por fazer parte do grupo de descendentes italianos.

\section{O museu “Casa dei Nonni”: memória ou nostalgia?}

Temos observado em nossa sociedade uma preocupação cada vez maior para com o passado. Nota-se essa característica, por exemplo, no design de eletrodomésticos, vestuários, artigos de decoração, entre outros produtos, que são inspirados no design das décadas de 70 e 80. Percebe-se, também, uma atenção maior para com os locais destinados a "preservar" a memória, como museus e memoriais (principalmente ligados às vítimas da Segunda Guerra Mundial). Desenvolve-se, também, uma obsessão por ruínas, que um dia foram a promessa de modernidade (Huyssen, 2014, p. 91). O que teria desencadeado essa preocupação para com o passado? O medo do esquecimento? Uma decepção com o presente? A falta de esperança no futuro? Um sentimento nostálgico?

Nos concentremos na última pergunta: o sentimento nostálgico. Pensar a nostalgia é um exercício que, primeiramente, requer uma discussão sobre o conceito de memória. Afinal, nem tudo o que se vivenciou no passado é digno de ser lembrado de maneira nostálgica. O que foi vivido é filtrado no/pelo presente. Dessa forma, a nostalgia também é seletiva.

Entendemos a memória como uma construção feita e atualizada constantemente no presente o que implica pensarmos em uma memória viva e que seleciona o que quer ser lembrado e esquecido. Dito isto, também não podemos desconsiderar o meio no qual a memória está sendo produzida, ou seja, os grupos sociais dos quais o sujeito que produz uma narrativa faz parte. Eclea Bosi afirma que a memória é fruto de uma construção social e é influenciada, entre outros elementos, pelos grupos sociais que o indivíduo fazia ou faz parte, como a Igreja, a escola, o trabalho, etc. (Bosi, 1994, p. 54). A memória é configurada pelas vivências e somente o que tem significância é lembrado, em outras palavras, "A memória é um cabedal infinito do qual só registramos um fragmento" (Bosi, 1994. p. 39).

Segundo Ecléa Bosi, a memória, além de permitir a relação do corpo presente com o passado, interfere no processo das representações:

Pela memória, o passado não só vem à tona das águas presentes, misturandose com as percepções imediatas, como também empurra, "desloca" estas últimas, ocupando o espaço todo da consciência. A memória aparece como força subjetiva ao mesmo tempo profunda e ativa, latente e penetrante, oculta $e$ invasora. (Bosi, 1994, p. 47) 
Se a memória é fruto de um processo de construção social e interfere nos processos de representação, a nostalgia também pode ser pensada como uma construção social. Nem todos os fatos do passado são lembrados nostalgicamente. Ninguém é nostálgico com acontecimentos trágicos ou momentos de sofrimento. Dessa forma, devemos pensar no que pode ou não ser considerado digno de nostalgia ou o que as pessoas selecionam para ser lembrado com um certo saudosismo.

O passado criado pela nostalgia nem sempre é o que realmente foi vivido. A nostalgia pode recriar lugares e memórias e construir um passado que nunca existiu, um passado imaginado e fictício.

[...] a atitude nostálgica não depende apenas do fascínio pela natureza irrecuperável do acontecido para afirmar a sua capacidade de atraç̧ão e o seu enorme impacto emocional. De facto, ela navega muitas vezes até um passado que jamais foi vivo, mas que é imaginado, idealizado, ou arquitetado a partir de modelos pré-estabelecidos, utilizando para esse efeito os diversos recursos do quais dispõe a memória colectiva adquirida, entre os quais se conta, com grande destaque, o discurso historiográfico. (Bebiano, 2006, p. 6)

Em consonância com a afirmação de Bebiano, a autora Svetlana Boym também aponta para a invenção de um passado pela nostalgia. Esta é definida pela autora como "um desejo por um lar que não existe mais ou nunca existiu. Nostalgia é um sentimento de perda $e$ deslocamento, mas é também uma fascinação com a própria fantasia” (Boym, 2017, p. 153). Assim, a nostalgia é uma construção de um passado ideal, um passado fictício que nunca existiu ou mesmo que não existe mais.

A nostalgia parte de pessoas que vivem no presente. Então, o que as leva a se afastarem de seu tempo - do tempo presente - e buscarem a reconstrução de um passado que não existe mais ou que nem ao menos existiu? O que tão desolador existe no presente?

Um texto que nos ajuda a pensar nessa questão é de autoria de Arnold Gehlen, intitulado "A felicidade evadida. Uma interpretação da nostalgia". Para Gehlen, o ponto crucial para entendermos esse retorno nostálgico ao passado é a busca pela felicidade. Nossa sociedade está mergulhada na lógica da valorização da aquisição de bens, sejam eles materiais ou simbólicos, porém, a partir do momento que conseguimos conquistar o que tanto queríamos, não mais valorizamos e nossos olhos se voltam para uma nova aquisição. Nas palavras de Gehlen, "somente o adquirir está envolto em prazer, não o possuir" (2017, p. 144).

Essa dinâmica pode ser observada nas propagandas de produtos, como celulares, TVs, computadores, roupas, calçados etc. A ideia é convencer de que tudo o que usamos está errado 
e ultrapassado e que uma nova compra tornará nossa vida mais prática e consequentemente mais feliz, mas logo depois novos produtos são lançados e a infelicidade retorna, até que uma nova compra seja realizada.

Nossa sociedade cria uma felicidade que é frágil e momentânea, pois ao mesmo tempo em que oferece a felicidade também vende a decepção (Gehlen, 2017, p. 145). Para Gehlen, a saída desse círculo vicioso é a criação de uma fantasia com imagens de felicidade e se essa felicidade for encontrada voltando-se para o passado, eis, aí, o lugar na nostalgia.

Já a autora Svetlana Boym, pensa a nostalgia sob um viés diferente. O conceito de nostalgia, segundo Boym, curiosamente, teria sido utilizado primeiramente na área da medicina no século XVII, por Jahanes Hofer. Para esse autor, a nostalgia era uma doença curável que acometia estudantes, empregados domésticos e soldados que saíam de seus países, inclusive, estes últimos, astutamente usavam essa "doença" para poderem voltarem para suas casas e fugirem da guerra. Porém, a nostalgia que interessa para a autora não é uma nostalgia individual, mas sim, "um sintoma de nossa época, uma emoção histórica" (2017, p. 154).

Para isso, Boym, aponta três observações sobre a nostalgia. Primeiro, a nostalgia não é anti-moderna, mas sim contemporânea da modernidade, resultado de uma nova compreensão do tempo e do espaço. Segundo, a nostalgia é o anseio por um tempo diferente, no qual parece ser a saudade de um lugar, mas é um anseio por outro tempo, com ritmos mais lentos. $\mathrm{E}$ terceiro, a nostalgia nem sempre é retrospectiva, pois as fronteiras sobre o passado têm um impacto direto sobre realidades do futuro. (2017, p. 154). Ao que parece, para a autora, a nostalgia seria uma fuga de ritmos acelerados modernos e a aproximação de ritmos mais lentos, o que não quer dizer que a nostalgia nega a modernidade, pelo contrário, é seu próprio sintoma.

De acordo com Boym, existem dois tipos de nostalgia: a restauradora e a reflexiva. A primeira seria uma nostalgia mais problemática, pois tenta "reconstruir uma terra perdida" na tentativa de proteger uma verdade. A segunda é a nostalgia que despreza "o retorno à casa" e se preocupa com o tempo histórico, não tendo o intuito de resgatar uma verdade.

A nostalgia restauradora enfatiza o nostos (casa) e enceta uma reconstrução transhistórica da terra perdida. A nostalgia reflexiva se desenvolve com a algia (o próprio anseio) e posterga o retorno à casa - melancolicamente, ironicamente, desesperadamente. [...]. A nostalgia restauradora não se percebe como nostalgia, mas antes como verdade e tradição. A nostalgia reflexiva reside na ambivalência do pertencimento e saudade humanos e não se desvia das contradições da modernidade. A nostalgia restauradora protege a verdade absoluta ao passo que a nostalgia reflexiva a coloca em dúvida. (Boym, 2017, p. 159) 
O assunto sobre o passado pode ser o mesmo, mas as duas formas de nostalgia contam histórias diferentes. Isso significa que é importante pensarmos nos problemas que a nostalgia pode desencadear. Um desses problemas é pensar que tipo de passado está sendo "resgatado" pela nostalgia e mais, quem está buscando esse passado. Essas questões são importantes para não cairmos na armadilha de seguirmos a nostalgia fabricada pelos outros (Boyn, 2017, p. 164).

Tanto Gehlen, quanto Boym, veem na própria modernidade uma das causas para o "efeito nostalgia". Para o primeiro a nostalgia seria uma fuga de uma sociedade caracterizada pelo tédio e pela busca constante da felicidade. Já para a segunda, a nostalgia é o próprio sentimento da modernidade, que tenta "fugir" de seu próprio tempo e ir para o passado na busca por ritmos mais lentos. Para esses autores, parece ser a modernidade a grande responsável pela produção do efeito-nostalgia.

A ideia de que nossa sociedade cada vez mais se volta para o passado também é discutida por Andreas Huyssen, no livro "Culturas do passado-presente". Nessa obra o autor toma como ponto de partida, para discutir a nostalgia, a reflexão sobre as ruínas do passado ainda existentes, as quais, segundo o autor, são desencadeantes poderosos da nostalgia (2014, p. 91). De acordo com Huyssen, nas últimas décadas desenvolveu-se uma obsessão pelas ruínas, o que revela a saudade de uma época em que ainda se podia imaginar um futuro e promessa de uma era moderna. Em outras palavras, nossa sociedade tornou-se nostálgica pela incerteza e descrença no futuro: "Temos saudade das ruínas da modernidade porque elas ainda parecem encerrar uma promessa que desapareceu da nossa era: a promessa de um futuro alternativo" (Huyssen, 2014, p. 93).

Tomemos como centro de análise o museu "Casa dei Nonni", localizado na comunidade de Pinho de Baixo, zona rural da cidade de Irati (ver imagem 1). O museu, inaugurado em 2016, foi construído com os materiais que eram de uma casa, da área urbana, de propriedade de Alzira Dembiski Bueno. Na ocasião, o imóvel precisou ser retirado para a construção de uma rotatória na região central da cidade. Os materiais foram, então, doados ao grupo "Chiaro di Luna", grupo folclórico italiano, que destinou-os para a construção de um museu em um terreno doado por uma das moradoras da comunidade de Pinho de Baixo. 


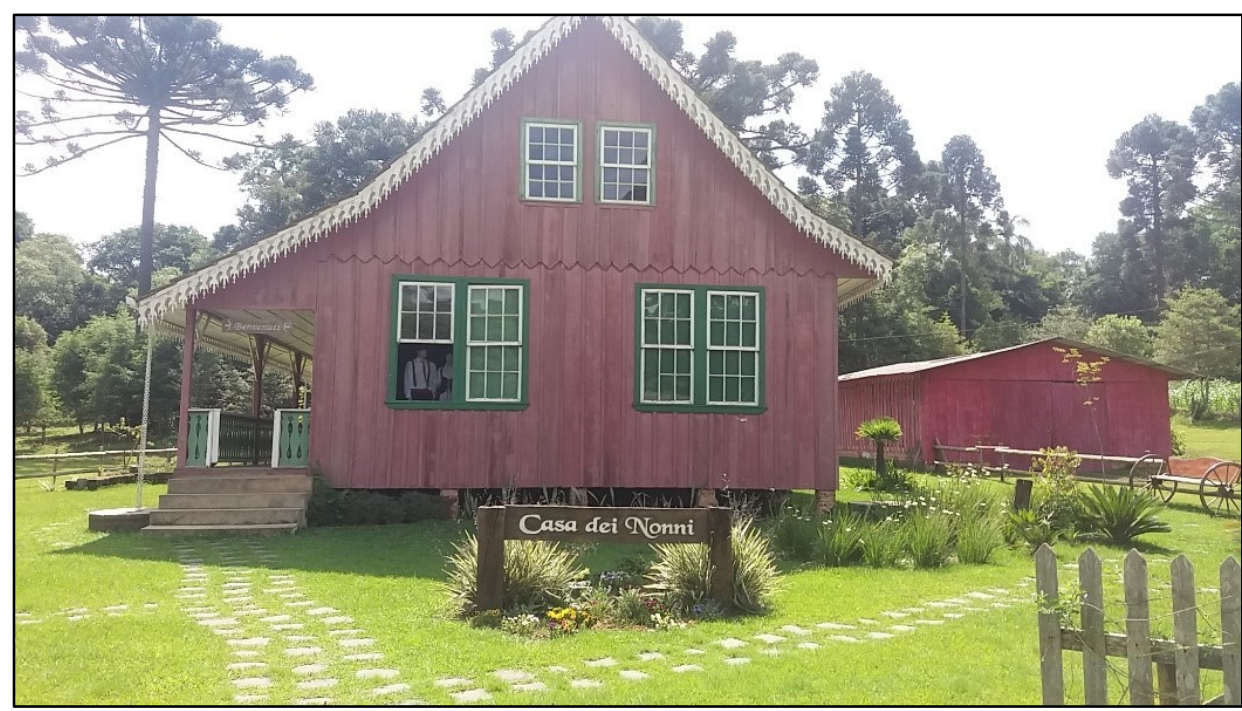

Fonte: Arquivo pessoal da autora. Foto tirada em 03/12/17

Após o término de sua construção, os integrantes do Chiaro di Luna se reuniram e decidiram que cada família doaria objetos antigos, que pertenceram a seus avós e bisavós, para fazerem parte do museu, conforme afirmou Rosa Romilde Zanlorensi, em entrevista a uma rádio local da cidade de Irati.

Segundo Romilde, após a construção, foi realizada uma reunião com todos os moradores. $\mathrm{Na}$ ocasião, foi solicitado que cada família levasse um objeto que pudesse ficar em exposição no museu. A moradora ressalta que os objetos contam um pouco da história da comunidade. "Tem descendentes que pessoas, como os meus bisavós, que vieram da Itália, e nós somos descendentes deles", declara. (Zanlorensi, 2016)

Os objetos doados, hoje, fazem parte do acervo do museu, tais como cama, cômodas, guarda-roupas, louças, vestuários, roupas de cama, artesanatos em brolha e crochê, utensílios utilizados para o trabalho na lavoura, fotografias, quadros, etc. Esses objetos eram de propriedade das famílias da comunidade de Pinho de Baixo e se tornaram referência para os moradores quando se fala em memória da imigração italiana.

O museu, construído de madeira, é dividido em duas áreas de visitação, uma que fica no térreo e um andar superior, representando um sótão. No andar térreo, existe um espaço destinado ao comércio de produtos alimentícios, como pães, licores, vinhos, geleias, biscoitos e também de artesanatos, como toalhas e algumas "lembrancinhas" com a inscrição do museu "Casa dei Nonni". Junto a esse espaço comercial estão expostos objetos relacionados ao trabalho agrícola e doméstico, os quais dividem o espaço com móveis de cozinha, como um guarda-louças e eletrodomésticos, como uma geladeira. Anexo, existe um cômodo no qual 
existem inúmeras fotos, máquinas de costura manuais e alguns móveis (ver imagem 2). As fotos, em sua maioria, retratam algumas famílias da comunidade em momentos festivos, principalmente em casamentos.

Imagem 2: Museu "Casa dei Nonni" - sala embaixo

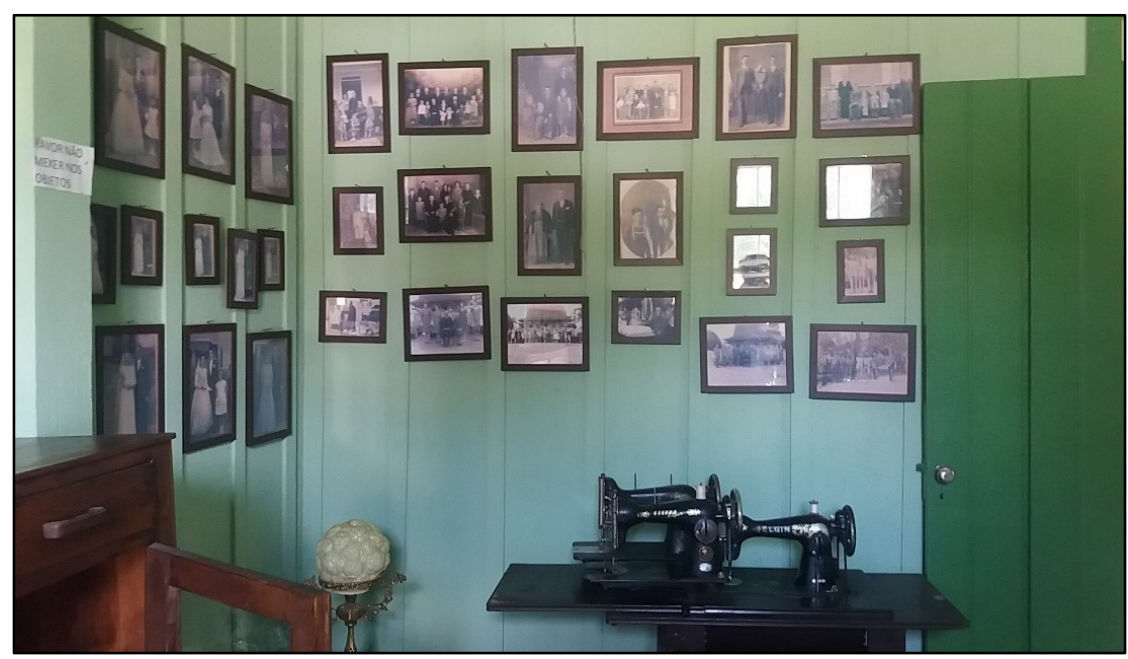

Fonte: Arquivo pessoal da autora. Foto tirada em 03/12/17.

Grande parte dos moradores são filhos, netos ou bisnetos de descendentes de italianos vindos de colônias localizadas em Campo Largo, atual região metropolitana de Curitiba. Em entrevistas realizadas, com frequência são mencionados locais como Rio Verde, Santa Felicidade, Rondinha, Balbino Cunha, todos em Campo Largo, como os lugares dos quais seus avós ou bisavós saíram para depois se fixarem em Irati. Constata-se, por meio de pesquisa bibliográfica, que esses lugares eram colônias italianas criadas entre o final da década de 70 e 90, do século XIX, conforme tabela abaixo:

Tabela 1: Colônias italianas em Campo Largo-PR. Fonte: Arquivo pessoal da autora. Foto tirada em 03/12/17.

\begin{tabular}{|c|c|c|c|c|c|}
\hline ANO & Colônia & $\begin{array}{c}\text { Distância da } \\
\text { Sede } \\
\text { municipal }\end{array}$ & $\begin{array}{c}\text { Área em } \\
\text { hectares }\end{array}$ & $\mathrm{N}^{\circ}$ de lotes & $\mathrm{N}^{\circ}$ de imigrantes \\
\hline 1878 & $\begin{array}{c}\text { Antônio } \\
\text { Rebouças ou } \\
\text { Timbituva }\end{array}$ & $14 \mathrm{~km}$ & 350,9 & 34 & 244 \\
\hline 1885 & $\begin{array}{c}\text { Mendes de Sá } \\
\text { ou Rondinha }\end{array}$ & $4 \mathrm{~km}$ & $2.000,0$ & 180 & 148 \\
\hline 1889 & $\begin{array}{c}\text { Balbino Cunha } \\
\text { ou Campina }\end{array}$ & $8 \mathrm{~km}$ & 225,9 & 25 & 122 \\
\hline
\end{tabular}




\begin{tabular}{|c|c|c|c|c|c|}
\hline 1889 & $\begin{array}{c}\text { Dona Mariana } \\
\text { ou Rio Verde }\end{array}$ & $8 \mathrm{~km}$ & 315,3 & 33 & 170 \\
\hline
\end{tabular}

Fonte: MACHADO, et ai. 1969, p. 164-167.

A escassez de terras nessas colônias, pode ter sido um dos fatores que contribuiu para que os descendentes tomassem a decisão de migrar. Se por um lado havia a falta de terras em Campo Largo, haja vista que os lotes já tinham determinada limitação em termos de extensão territorial, em Irati ocorria o contrário: abundância de terras e baixo custo dessas propriedades ${ }^{3}$.

Após deixarem as colônias de Campo Largo, houve a instalação desses descendentes em áreas rurais de Irati, como foi o caso de comunidades como Rio do Couro, Mato Queimado e Pinho de Baixo 4 . Atualmente, essas localidades possuem uma quantidade significativa de pessoas com descendência italiana, porém, Pinho de Baixo é sempre mencionada como referência na cidade de Irati quando se fala em imigração italiana. Tendo uma quantidade representativa de moradores descendentes de italianos, a comunidade além de ter o museu, também conta com o grupo folclórico "Chiaro di Luna" e com a realização anual da "Festa da Polenta $5 "$.

No caso do museu "Casa dei Nonni", entendemos esse espaço enquanto um local de fabricação da memória italiana que parte do presente e não como a "cristalização" da memória. O conceito de "lugares de memória", defendido por Pierre Nora em um texto de 1984, intitulado "Entre memória e história: a problemática dos lugares", indica uma ruptura historiográfica francesa em relação à identidade nacional resultando na ausência de meios para a memória $e$ surgindo, assim, a necessidade dos "lugares de memória". Os "lugares de memória", para Nora, "nascem e vivem do sentimento que não há memória espontânea" (1993, p. 13), o que pressupõe uma certa "fabricação" e "cristalização" da memória.

Pensar os "lugares de memória" enquanto um local em que a memória está depositada objetivamente nos dá a impressão de somente acomodar e guardar documentos, adquirindo o sentido de um repositório. Assim, "a ideia de repositório acaba por contaminar a de memória, que, por ser percebida como 'guardada' (protegida, assegurada) em um 'lugar' física e geograficamente identificável, é reificada, 'coisificada'” (Gonçalves, 2015, p. 16). Uma possibilidade para não "coisificarmos" a memória do museu Casa dei Nonni e que nos pareceu ser bastante interessante é a utilização do conceito de "vetores de memória".

O conceito de "vetores de memória", diferentemente de "lugares de memória" nos permite pensar sobre a capacidade de mobilização da memória e os diferentes significados que lhes são atribuídos, os quais são modificáveis ao longo do tempo (Gonçalves, 2015, p. 17). Os 
objetos que estão em um museu, por exemplo, não comportam por si só a memória, mas despertam em quem os observa diferentes interpretações e sentidos, ou seja, acabam mobilizando e conduzindo a memória.

Refletindo sobre o museu "Casa dei Nonni", uma das partes que compõe seu acervo é voltada para objetos que eram utilizados para o trabalho, especialmente agrícola e doméstico. $\mathrm{Na}$ imagem 3, podemos visualizar instrumentos como enxadas, cerrotes, machados, ferraduras $e$ também utensílios domésticos como ferro de passar roupas à brasa, panelas, chaleiras, máquinas de moer carne, peneiras, "máquina" (feita artesanalmente) para moer uvas para a fabricação do vinho, entre outros. Esses objetos eram de propriedade das famílias de descendentes de italianos da localidade de Pinho de Baixo e foram doados para o museu logo após sua construção, conforme exposto anteriormente.

Imagem 3: Objetos de uso doméstico e agrícola.

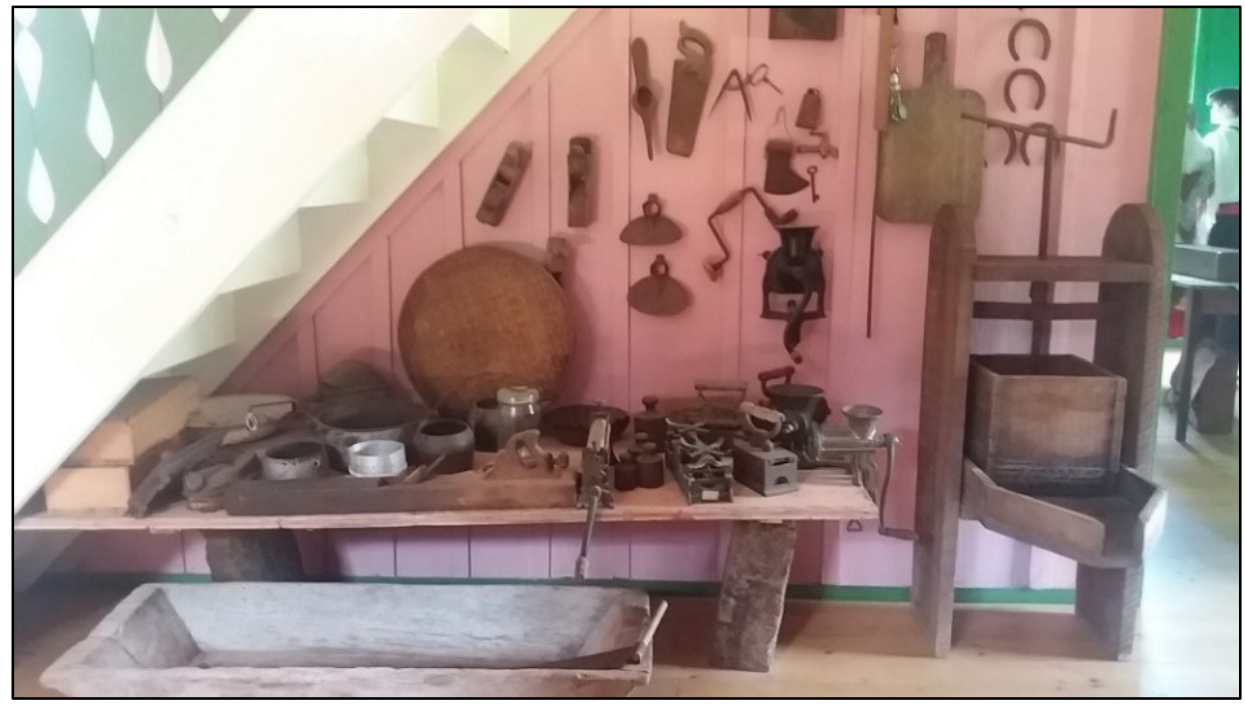

Fonte: Arquivo pessoal da autora. Foto tirada em 03/12/17.

O museu recebe um público diversificado, como pessoas da própria localidade e de localidades vizinhas, até mesmo de outras cidades, alunos de escolas e universidades, pessoas da área urbana e da área rural, homens e mulheres, enfim, são pessoas com idades e vivências diferentes. Cada pessoa que visita o museu possui uma trajetória de vida diferente e ao observar esses objetos podem ter diferentes interpretações e o despertar das mais variadas memórias. Para uma pessoa de idade mais avançada que conheceu esses objetos no trabalho diário, a memória pode estar ligada a um período de vida difícil do serviço na roça ou até mesmo à saudade daquela época. Talvez, esses objetos despertem a lembrança de pessoas que lhes ensinaram a utilizá-los, despertem a memória de conversas, cheiros, sabores. Ou talvez, para o 
público mais jovem, os objetos sejam interpretados como sinônimo do atraso industrial, em que o serviço era realizado, em sua maioria, pela força humana. Isso mostra que os objetos não comportam a memória em si, mas conduzem a diferentes percepções e sentidos. Cada objeto pode despertar lembranças diferentes, eles têm a capacidade de mobilizar a memória, ativá-la, fazê-la trabalhar.

Entre as memórias que os objetos que fazem parte de um museu podem despertar em quem os observa, destacamos a nostálgica. A nostalgia pode ser entendida como uma espécie de "fabricação", "criação" do passado, o que significa pensarmos em uma idealização de algo que, talvez, nunca fora vivenciado (Bebiano, 2006, p. 6). Não estamos afirmando a existência de um tipo de memória "verdadeira", que deve ser positivada, em oposição à uma memória nostálgica que "projeta" um passado e que, portanto, deve ser descartada por ser uma invenção. Pelo contrário, estamos chamando a atenção para os sentimentos que a memória pode despertar.

Como exemplo, podemos analisar outro ambiente do museu "Casa dei Nonni" (ver imagem 4), que foi a (re)criação de um quarto, considerado como tradicional nas casas dos "nonnos". Na foto, podemos notar a presença de quadros de santos, rosário, calçados, tapetes e roupa de cama feitos de crochê, berço, vestimentas, baú e, até mesmo, um penico. A riqueza de detalhes demonstra a preocupação em fazer com que quem visualize o quarto possa imaginar como eram esses cômodos há tempos atrás. E mais, como a memória é mobilizada e atualizada a partir do presente, ao observar o quarto e os objetos nele dispostos, o visitante pode despertar memórias nostálgicas ligadas à sua infância, ao convívio com seus pais e avós e a forma como tais objetos eram utilizados.

Imagem 4: Quarto do museu.

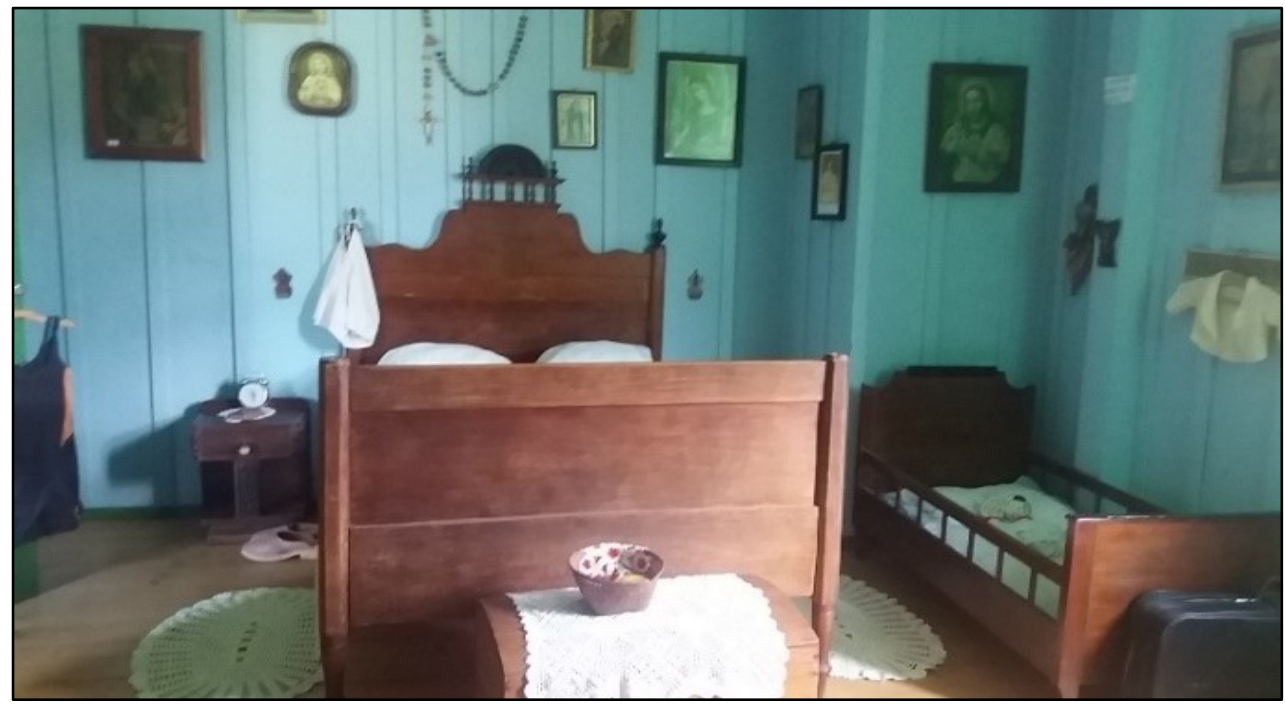


Fonte: Arquivo pessoal da autora. Foto tirada em 03/12/17.

Um quarto organizado dessa forma pode ter sido fruto e objeto de uma memória nostálgica, que é caracterizada pelo "desejo por um lar que não existe mais ou nunca existiu" e também pela saudade de um tempo com ritmos mais lentos (Boym, 2017, p. 153-154). Nas duas formas de nostalgia apontadas por Svetlana Boym, restauradora e reflexiva, podemos relacionar o quarto à restauradora, que segundo a autora, não se reconhece enquanto nostalgia, mas sim, como verdade absoluta e tradição (2017, p. 159).

Também é importante refletirmos sobre as possíveis fabricações nostálgicas, ou seja, quem fala em nome da nostalgia? Isso significa pensarmos nos problemas que podem se desencadear, como por exemplo, que tipo de passado está sendo "resgatado" pela nostalgia e mais, quem está buscando esse passado. Essas questões são importantes para não cairmos na armadilha de seguirmos uma nostalgia fabricada pelos outros (boyn, 2017, p. 164). Assim, finalizamos a discussão com algumas perguntas: que tipo de memória está sendo "resgatada" pelo "Casa dei Nonni"? Quem está falando em nome da nostalgia?

\section{Considerações finais}

Neste artigo procuramos desenvolver uma discussão a respeito de algumas práticas culturais realizadas por um grupo de descendentes italianos, os quais partiram de colônias de Campo Largo- PR nas primeiras décadas do século XX e se fixaram em áreas rurais da cidade de Irati-PR. Em uma dessas comunidades, Pinho de Baixo, os descendentes criaram um grupo folclórico chamado "Chiaro di Luna", que organiza, anualmente, uma festa considerada típica italiana, a "Festa da Polenta" e também coordena o museu "Casa dei Nonni", objeto central de análise desse artigo. A partir dessas manifestações culturais e identitárias, procuramos desenvolver uma discussão sobre alguns conceitos trabalhados por autores na área da História do Tempo Presente e como esse campo de conhecimento pode contribuir, teórico e metodologicamente, para realização de nossa pesquisa.

A História do Tempo Presente apresenta reflexões significativas e que contribuem de maneira importante para nosso trabalho, pois nosso recorte temporal permite que as pessoas que fizeram parte da construção do museu e do grupo que mantem essa instituição, o "Chiaro di Luna", possam testemunhar sobre determinados acontecimentos. Isso implica em um cuidado 
redobrado, pois essas pessoas podem não concordar com nossas interpretações históricas, conforme já alertado por Henry Rousso.

Além da discussão sobre História do Tempo Presente, para analisar a organização do museu, buscamos leituras em trabalhos relacionados à memória e nostalgia. Esses dois conceitos guiaram nossas discussões. A memória, atualizada a partir do presente, é moldável dependendo dos grupos sociais dos quais os sujeitos que narram fizeram parte. Em nosso trabalho entendemos o museu não apenas como um "lugar de memória", conceito cunhado por Nora, mas também como "vetor de memória", o que significa que cada objeto e espaço do museu despertam lembranças e sentimentos diferenciados, dependendo da história de vida de cada visitante. Dessa maneira, se fez necessária a discussão sobre a nostalgia, que é entendida por alguns autores, como Svetlana Boym, como o desejo por um lar que não existe mais, assim, a memória nostálgica acaba criando uma espécie de verdade absoluta.

Apesar de ser um campo relativamente recente na historiografia, a HTP tem muito a contribuir, especialmente com temas que utilizam os testemunhos como fontes documentais. Nosso trabalho buscou discutir sobre a HTP a partir de seus marcos teóricos, mostrando como estes podem ser fundamentais para se compreender algumas práticas culturais dos descendentes de italianos em Irati, como o museu "Casa dei Nonni". Ao mesmo tempo, nos alerta para os cuidados que devemos ter para com a utilização dos testemunhos, uma vez que nossa escrita pode ser questionada, afinal, estamos vivenciando o mesmo tempo que nossos objetos de estudo.

\section{Referências}

AGGIO, Osmar. A colônia que veio do pó. [S.1.] Gráfica Planeta Ltda, 2005.

BEBIANO, Rui. Nostalgia e imaginação: dois factores dinâmicos num mundo global. Disponível em: https://estudogeral.sib.uc.pt/bitstream/10316/43099/1/Nostalgia\%20e\%20imagina\%C3\%A7\%C3\%A3o dois\%2 Ofactores\%20din\%C3\%A2micos\%20num\%20mundo\%20global.pdf. Acesso em 03/11/17.

BÉDARIDA, François. Tempo presente e presença da História. In: FERREIRA, Marieta de M., AMADO, Janaína (orgs.). Usos E̊ abusos da História Orai. Rio de Janeiro: Ed. FGV, 1996, p. 219-229.

BOYM, Svetlana. Mal estar na nostalgia. História da Historiografia, Ouro Preto, n. 23, 2017, p. 153-165.

DOSSE, François. História do Tempo Presente e Historiografia. Tempo e Argumento, Florianópolis, v. 4, n. 1, 2012, p. 5-22. 
GEHLEN, Arnold. A felicidade evadida: uma interpretação da nostalgia. História da Historiografia, Ouro Preto, n. 23, 2017, p. 142-152.

GONÇALVES, Janice. Lugares de memória, memórias concorrentes e leis memoriais. Revista Memória em Rede, Pelotas, v. 7, n. 13, 2015, p. 15-28.

HUYSSEN, Andreas. A cultura da memória em um impasse: memoriais em Berlim e Nova York. Usos tradicionais do discurso sobre o Holocausto e o colonialismo. In: Culturas do passado-presente: modernismos, artes visuais, políticas da memória. Rio de Janeiro: Contraponto, Museu de Arte do Rio, 2014.

MACHADO, Brasil Pinheiro; BALHANA, Altiva P.; WESTHEPHALEN, M. Cecília. História do Paraná. Curitiba: Gráfica Editora Paraná Cultural LTDA, 1969.

MANEIRA, Regiane. Compra e venda de terras por descendentes de imigrantes italianos em Irati. In: PRADO, Anderson; ANTUNES, Jair; COSTA, Lourenço R. da. (orgs.). Diversidade étnica e cultural no interior do Paraná. São Leopoldo: Oikos, 2016.

NORA, Pierre. Entre memória e história: a problemática dos lugares. Projeto História, São Paulo, n. 10, 1993, p. $7-28$.

ORREDA, J. Irati. Volume II. Irati: Editora Sul-Oeste do Paraná, 1974.

ROUSSO, Henry. A última catástrofe: a história, o presente, o contemporâneo. Rio de Janeiro: Ed. FGV, 2016.

ZANLORENSI, Romilde Rosa. Entrevista concedida à Radio Najuá. Irati, 2016. Disponível em: http://radionajua.com.br/noticia/noticias/irati-e-regiao/pinho-de-baixo-passa-a-contar-com-museu-dacomunidade/33639/. Acesso em 28/01/2019.

\footnotetext{
1 "Casa dos Nonnos", que significa "casa dos avós".

${ }^{2}$ Nesse artigo não serão analisadas as entrevistas, pois nosso intuito é apresentar algumas discussões referentes à História do Tempo Presente e como esta pode contribuir para as pesquisas que utilizam o testemunho oral como fonte histórica, em nosso caso para compreender o processo de construção do museu.

${ }^{3}$ Esse tema foi explorado com mais detalhes no capítulo "Compra $e$ venda de terras por descendentes de imigrantes italianos em Irati", publicado no livro "Diversidade étnica e cultural no interior do Paraná", publicado pela editora Oikos, em 2016.

${ }^{4}$ Nesse período a localidade pertencia ao município de Imbituva-PR.

${ }^{5}$ A festa foi realizada anualmente até 2018 , ano que não houve a realização do evento. A festa consiste em um jantar com comidas consideradas típicas italianas, como a polenta, alguns tipos de massas, como lasanha e macarrão, e o vinho, este último produzido pelas famílias da localidade. Durante a realização do jantar, também são comercializados produtos como pães, bolachas, geleias, doces, embutidos, queijos, entre outros produtos.
} 